\title{
Numerical Simulation of Flash Reduction of Iron Ore Particles with Biomass Syngas
}

\author{
Xingnan WANG, ${ }^{1,2)}$ Guiqin $\mathrm{FU}^{1,2)}$ Wei $\mathrm{LI}^{1,2) *}$ and Miaoyong $\mathrm{ZHU}^{1,2)}$ \\ 1) Key Laboratory for Ecological Metallurgy of Multimetallic Mineral (Ministry of Education), Northeastern University, \\ Shenyang, 110819 China. \\ 2) School of Metallurgy, Northeastern University, Shenyang, 110819 China.
}

(Received on June 21, 2021; accepted on October 13, 2021; J-STAGE Advance published date: December 25, 2021)

\begin{abstract}
Flash ironmaking technology has recently been developed to directly reduce in-flight hematite ore particles in a few seconds using gas reductant. Using biomass syngas as the reducer of this technology can decrease fossil fuel consumption and carbon dioxide emissions. This study investigated the flash reduction behavior of hematite particles using biomass syngas in a drop tube reactor based on a threedimensional Eulerian-Lagrangian CFD model that includes heat and mass transfer, heterogeneous and homogeneous reactions, radiation, and interactions between gas and particles. The effects of the reduction temperature, biomass gas composition, and pressure on the reduction process were explored. Moreover, the particle characteristics and reaction rate during the flash reduction process were presented. The results showed that the water gas shift reaction proceeded in the reverse direction, and the methane steam reforming reaction proceeded in the forward direction during the flash reduction process. Under biomass steam gasification syngas, the reduction degree of hematite ore particles reached $95.90 \%$ within $1.4 \mathrm{~s}$ at $1573 \mathrm{~K}$. Also, a higher temperature and operating pressure favored the reduction process by accelerating the reduction rate of hematite. These results provide a theoretical basis for using biomass syngas in flash ironmaking technology.
\end{abstract}

KEY WORDS: simulation; flash reduction; hematite particles; biomass syngas; reduction degree.

\section{Introduction}

The traditional ironmaking process is dominated by a blast furnace, which is associated with high energy consumption and $\mathrm{CO}_{2}$ emissions. In recent years, flash ironmaking technology has become an alternative ironmaking option, as it can directly reduce fine iron ore using a gas reductant, which bypasses the sintering/pelletization steps of blast furnace and avoids sticking/agglomeration associated with fluidized bed. ${ }^{1,2)}$ During the flash ironmaking process, fine iron ore and flux are injected into a flash furnace along with a reductive gas and rapidly pre-reduced by the reductive gas during the in-flight process. Then, the final reduction of iron ore is carried out in a smelting bath to produce metallic iron. The utilization of cleaner and high-reactive gases such as hydrogen and natural gas during the reduction process can significantly reduce $\mathrm{CO}_{2}$ emissions and save energy.

Currently, the syngas (such as purified COREX, dry pulverized coal gasification, water-coal slurry gasification, and

* Corresponding author: E-mail: 1w_neu@126.com reformed coke oven gas) used in the traditional gas-based reduction process is obtained primarily from fossil fuels, including coal, natural gas, and metallurgical coke. Fossil fuels are becoming scarcer as their consumption increases. To reduce the fossil fuel dependence of the ironmaking process, it is of great strategic importance to identify a renewable reducing fuel. Biomass is an abundant, renewable, and environmentally friendly reducing agent that can be obtained from many fields such as agricultural residues, food waste, and industrial by-products, and it shows great potential for future development. ${ }^{3)}$ The use of biomass to produce syngas has exhibited promising prospect and has received extensive attention. ${ }^{4-8)}$ Through gasification technology with different gasification media such as air, oxygen and steam, biomass is partially oxidized to convert carbonaceous feed stock into gas mixtures that include $\mathrm{CO}$, $\mathrm{CO}_{2}, \mathrm{CH}_{4}, \mathrm{H}_{2}$ and $\mathrm{H}_{2} \mathrm{O}$.

When gasification technology is used, biomass produces reductive gases that can be utilized to reduce iron oxide. $\mathrm{CO}_{2}$ and $\mathrm{H}_{2} \mathrm{O}$ produced during the reduction process diffuse into the atmosphere. Plants absorb $\mathrm{CO}_{2}$ and $\mathrm{H}_{2} \mathrm{O}$ through photosynthesis and convert them into biomass that can in 
turn be applied in the ironmaking process. Using biomass to produce syngas as the reductant can partly compensate for the utilization of natural gas or coal, decreasing the consumption of fossil fuels and reducing $\mathrm{CO}_{2}$ emissions. The utilization of biomass syngas in ironmaking technology has attracted attention, and extensive investigations have been carried out. $^{9-11)}$ Guo et al. ${ }^{12,13)}$ investigated the reduction of oxidized iron ore pellets and iron ore/biomass composite pellets using biomass syngas as the reductant. Luo et al. ${ }^{14)}$ used biomass-generated syngas for the direct reduction of mixed biomass- $\mathrm{Fe}_{2} \mathrm{O}_{3}$ briquettes and found that biomass syngas has broad application prospects in the ironmaking technology. These studies showed that biomass syngas is a promising, potential alternative to fossil fuels used in the ironmaking industry; therefore, it is expected to be used as a reductant in flash ironmaking technology.

The flash reduction process is a complex multiphase flow reduction process that includes gas-particle interactions, mass and heat transfer, and reaction kinetics. In order to investigate the feasibility of using biomass syngas as the reductant for the flash reduction of hematite ore particles, it is extremely important to understand the flash reduction process occurring in a reactor. In recent years, with the development of computer technology, computational fluid dynamics (CFD) models have played an important role in revealing the flow, heat transfer, and chemical reactions inside reactors. ${ }^{15,16)}$ Moreover, CFD model has become a cost effective tool to predict and optimize reaction process. ${ }^{17)}$ Several studies used mathematical models to investigate the reduction of fine iron ore particles during the in-flight process. ${ }^{18-23)}$ For instance, Fan et al. ${ }^{18)}$ established a three-dimensional (3D) CFD model for simulating the flash reduction process of magnetite in $\mathrm{H}_{2}$ within a laboratory flash reactor to reveal the fluid flow, heat transfer, and chemical reactions occurring in a reactor. Abolpour et al. ${ }^{19)}$ investigated the in-flight motion of magnetite ore particles in the flash reduction process under a $\mathrm{CO}-\mathrm{Ar}$ gaseous mixture through a mathematical model. Abdelghany et al. ${ }^{20,21)}$ used a CFD approach to model the gas and particles flow in the flash ironmaking process based on the partial combustion of natural gas. Yang et al. ${ }^{22,23)}$ established a 3D CFD model to investigate the combined coal gasification and flash ironmaking process and analyze the turbulent structure, temperature/species distribution, and particle motion. The authors ${ }^{24)}$ studied the flash reaction process of hematite particles with six hydrogen-rich gases (including $\mathrm{H}_{2}, \mathrm{H}_{2} \mathrm{O}$, $\left.\mathrm{CO}, \mathrm{CO}_{2}\right)$ in a drop tube reactor. However, to the best of our knowledge, no work has reported numerical models for the flash reduction process of hematite ore in biomass syngas including $\mathrm{H}_{2}, \mathrm{H}_{2} \mathrm{O}, \mathrm{CO}, \mathrm{CO}_{2}, \mathrm{CH}_{4}$, etc. Compared to the single reducing atmosphere and hydrogen-rich atmosphere, there may be complex homogeneous and heterogeneous chemical reactions in the flash reduction process using biomass syngas. Thus, it is necessary to establish a mathematical model of the flash reduction of hematite ore in biomass syngas to reveal the complex multiphase flow in the reduction process.

In this study, a 3D CFD model was established to describe the hematite particle characteristics during flash reduction in a drop tube reactor. Four biomass syngas produced by different gasification media including air, oxygen-enriched air, oxygen, and steam were adopted as the reductants. The effects of reduction temperature, gas composition and operating pressure on the reduction process were measured. The particle temperature and reduction degree of hematite ore particles, gas distribution, and the reaction rate in the reactor were detailed to understand the flash reduction process.

\section{Thermodynamic Analysis}

Wood is a common biomass feedstock. Shayan et al. ${ }^{25)}$ used a thermodynamic equilibrium model to investigate the wood gasification process under four gasification agents, namely: air (21 mol\% $\mathrm{O}_{2}-79 \mathrm{~mol} \% \mathrm{~N}_{2}$ ), oxygen-enriched air (35 mol\% $\mathrm{O}_{2}-65 \mathrm{~mol}^{\%} \mathrm{~N}_{2}$ ), oxygen (95 $\mathrm{mol}^{2} \mathrm{O}_{2}-5$ mol $\% \mathrm{~N}_{2}$ ), and steam. The obtained four syngas produced by biomass air gasification (BAG), biomass $\mathrm{O}_{2}$-enriched air gasification (BOEG), biomass $\mathrm{O}_{2}$ gasification (BOG) and biomass steam gasification (BSG), and the gas compositions are shown in Table 1. To investigate the flash reduction behavior of hematite particles within the biomass syngas, the four biomass syngas were dried and adopted as reductants in this study, as shown in Table 2.

Before establishing the model, it is worthwhile determining the homogeneous and heterogeneous reactions occurring within the reduction temperature range (1 273-1 $673 \mathrm{~K}$ ). To ensure that the CFD model takes into account the chemical reactions occurring in the flash reduction process of hematite with biomass syngas at $1273-1673 \mathrm{~K}$, the equilibrium compositions of $\mathrm{Fe}_{2} \mathrm{O}_{3}$-biomass syngas systems were characterized using the Equilib module of FactSage 7.1 software, which is based on the Gibbs free energy minimization method. These calculations were carried out by assuming that reactions occurred at 1.0 atm pressure in a closed system. The FactPS and FToxid databases were chosen for the gas and oxide phases. Moreover, according to the metallic iron curve, the thermodynamic limit of the hematite reduction in biomass syngas can be determined.

The equilibrium composition of $0.1 \mathrm{~mol} \mathrm{Fe}_{2} \mathrm{O}_{3}$ and 1.0 mol biomass syngas was calculated within the temperature range of 273-1 $673 \mathrm{~K}$, as shown in Fig. 1. The curve

Table 1. The original biomass gasification syngas. ${ }^{25)}$

\begin{tabular}{ccccccc}
\hline $\begin{array}{c}\text { Biomass } \\
\text { syngas }\end{array}$ & $\begin{array}{c}\mathrm{H}_{2} \\
(\mathrm{vol} \%)\end{array}$ & $\begin{array}{c}\mathrm{CO} \\
(\mathrm{vol} \%)\end{array}$ & $\begin{array}{c}\mathrm{CO}_{2} \\
(\mathrm{vol} \%)\end{array}$ & $\begin{array}{c}\mathrm{H}_{2} \mathrm{O} \\
(\mathrm{vol} \%)\end{array}$ & $\begin{array}{c}\mathrm{CH}_{4} \\
(\mathrm{vol} \%)\end{array}$ & $\begin{array}{c}\mathrm{N}_{2} \\
(\mathrm{vol} \%)\end{array}$ \\
\hline BAG & 19.78 & 23.19 & 8.91 & 7.03 & 0.94 & 39.65 \\
BOEG & 26.2 & 31.25 & 10.15 & 7.87 & 1.65 & 22.87 \\
BOG & 34.13 & 41.51 & 11.81 & 8.98 & 2.81 & 0.75 \\
BSG & 48.92 & 35.27 & 5.83 & 7.48 & 0.31 & 0 \\
\hline
\end{tabular}

Table 2. The dried biomass gasification syngas used in this study.

\begin{tabular}{cccccc}
\hline $\begin{array}{c}\text { Dried biomass } \\
\text { syngas }\end{array}$ & $\begin{array}{c}\mathrm{H}_{2} \\
(\mathrm{vol} \%)\end{array}$ & $\begin{array}{c}\mathrm{CO} \\
(\mathrm{vol} \%)\end{array}$ & $\begin{array}{c}\mathrm{CO}_{2} \\
(\mathrm{vol} \%)\end{array}$ & $\begin{array}{c}\mathrm{CH}_{4} \\
(\mathrm{vol} \%)\end{array}$ & $\begin{array}{c}\mathrm{N}_{2} \\
(\mathrm{vol} \%)\end{array}$ \\
\hline BAG & 21.39 & 25.08 & 9.63 & 1.02 & 42.88 \\
BOEG & 28.44 & 33.92 & 11.02 & 1.79 & 24.83 \\
BOG & 37.5 & 45.61 & 12.98 & 3.09 & 0.82 \\
BSG & 54.16 & 39.05 & 6.45 & 0.34 & 0 \\
\hline
\end{tabular}



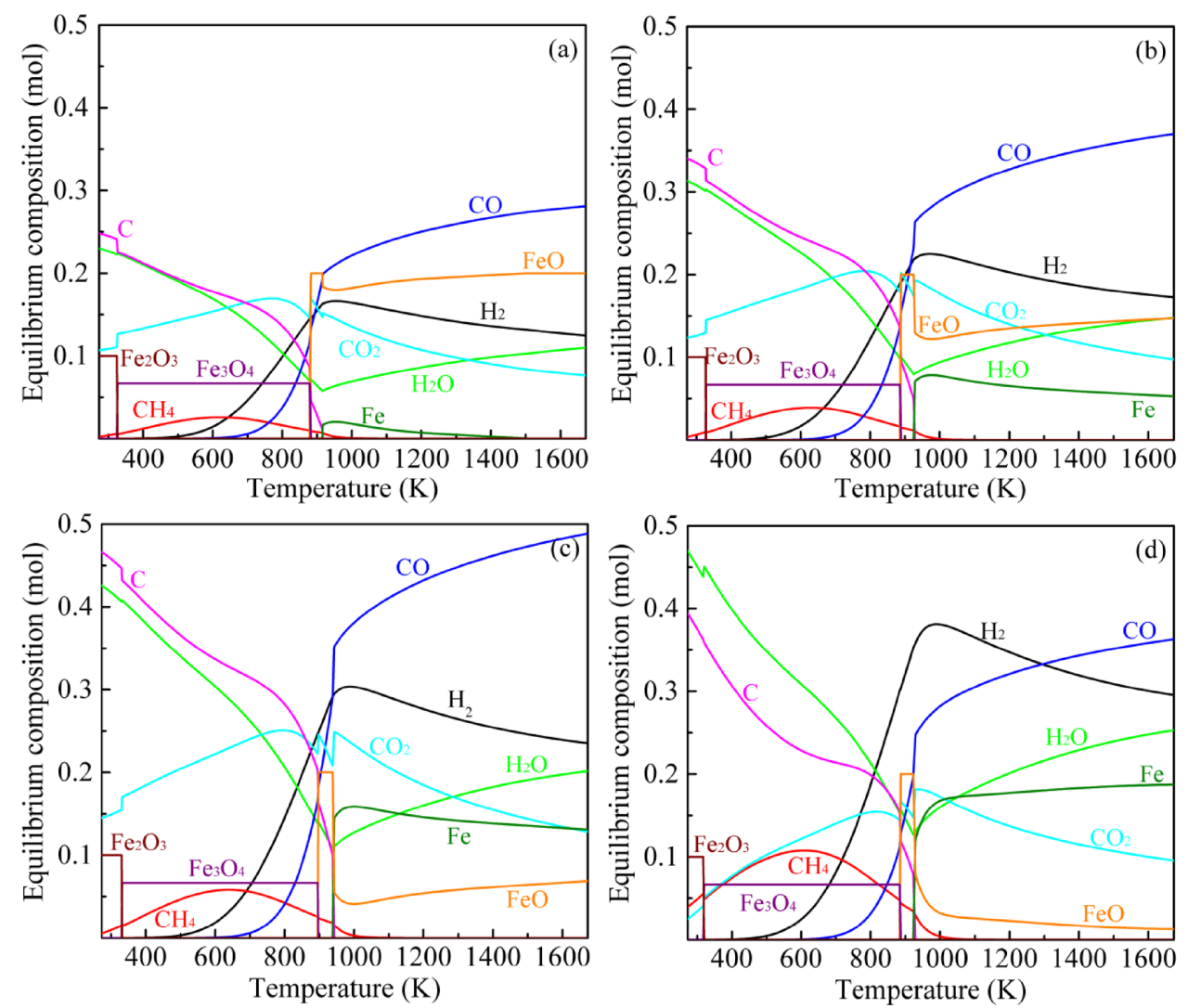

Fig. 1. Equilibrium compositions of 0.1 mole $\mathrm{Fe}_{2} \mathrm{O}_{3}$ with 1.0 mole different biomass syngas: (a) BAG, (b) BOEG, (c) BOG, and (d) BSG. (Online version in color.)

of $\mathrm{N}_{2}$ was ignored since the $\mathrm{N}_{2}$ content remained constant. From Fig. 1, when the temperature was above $1273 \mathrm{~K}$, the gas phase consisted of $\mathrm{CO}, \mathrm{H}_{2}, \mathrm{H}_{2} \mathrm{O}$, and $\mathrm{CO}_{2}$, and the solid phase was only composed of $\mathrm{FeO}$ and $\mathrm{Fe}$ (without $\mathrm{Fe}_{2} \mathrm{O}_{3}$ and $\mathrm{Fe}_{3} \mathrm{O}_{4}$ ) in all reaction systems. This implies that iron oxide was reduced by $\mathrm{CO}$ and $\mathrm{H}_{2}$ (Eqs. (R1)-(R6)) during the reduction process. Above $1273 \mathrm{~K}$, upon increasing the temperature, the contents of $\mathrm{H}_{2}$ and $\mathrm{CO}$ decreased and the contents of $\mathrm{CO}$ and $\mathrm{H}_{2} \mathrm{O}$ increased in the reaction system. This means the water gas shift reaction (WGSR) (Eq. (R7)) occurred during the reduction process. The initial biomass syngas contained a small amount of $\mathrm{CH}_{4}$, but $\mathrm{CH}_{4}$ was completely consumed above $1273 \mathrm{~K}$ as a result of the methane steam reforming reaction (MSRR) (Eq. (R8)). Since $\mathrm{CH}_{4}$ was absent above $1273 \mathrm{~K}$, the $\mathrm{CH}_{4}$ reduction reaction (Eq. (R9)) in the reduction process can be ignored. Moreover, the Boudouard reaction (Eq. (R10)) and the $\mathrm{Fe}_{3} \mathrm{C}$ formation reaction (Eq. (R11)) cannot occur because of the absence of $\mathrm{C}$ and $\mathrm{Fe}_{3} \mathrm{C}$ in the reaction systems. In conclusion, based on the thermodynamic analysis results, in the reduction process of hematite with these four biomass syngas at $1273-1673 \mathrm{~K}$, the $\mathrm{H}_{2}$ and $\mathrm{CO}$ reduction reactions, MSRR and WGSR may occur. Therefore, only these reactions were taken into account in the CFD model used in this study.

$$
\begin{aligned}
3 \mathrm{Fe}_{2} \mathrm{O}_{3}+\mathrm{CO} & \rightarrow 2 \mathrm{Fe}_{3} \mathrm{O}_{4}+\mathrm{CO}_{2} \\
\mathrm{Fe}_{3} \mathrm{O}_{4}+\mathrm{CO} & \rightarrow 3 \mathrm{FeO}+\mathrm{CO}_{2} \ldots \\
\mathrm{FeO}+\mathrm{CO} & \rightarrow \mathrm{Fe}+\mathrm{CO}_{2} \ldots \ldots \\
3 \mathrm{Fe}_{2} \mathrm{O}_{3}+\mathrm{H}_{2} & \rightarrow 2 \mathrm{Fe}_{3} \mathrm{O}_{4}+\mathrm{H}_{2} \mathrm{O}
\end{aligned}
$$

$$
\begin{aligned}
& \mathrm{Fe}_{3} \mathrm{O}_{4}+\mathrm{H}_{2} \rightarrow 3 \mathrm{Fe} \mathrm{O}+\mathrm{H}_{2} \mathrm{O} \\
& \mathrm{FeO}+\mathrm{H}_{2} \rightarrow \mathrm{Fe}+\mathrm{H}_{2} \mathrm{O} \\
& \mathrm{CO}+\mathrm{H}_{2} \mathrm{O} \leftrightarrow \mathrm{H}_{2}+\mathrm{CO}_{2} \\
& \mathrm{CH}_{4}+\mathrm{H}_{2} \mathrm{O} \leftrightarrow \mathrm{CO}+3 \mathrm{H}_{2} \\
& 3 \mathrm{CH}_{4}+\mathrm{Fe}_{2} \mathrm{O}_{3} \rightarrow 2 \mathrm{Fe}+3 \mathrm{CO}+6 \mathrm{H}_{2} \\
& 2 \mathrm{CO} \rightarrow \mathrm{C}+\mathrm{CO}_{2} \\
& 3 \mathrm{Fe}+\mathrm{C} \rightarrow \mathrm{Fe}_{3} \mathrm{C}
\end{aligned}
$$

As seen in Fig. 1, $\mathrm{Fe}_{2} \mathrm{O}_{3}$ was converted into $\mathrm{FeO}$ and $\mathrm{Fe}$ in the syngas of BAG, BOEG, BOG, and BSG under a limited gas supply condition, and the Fe content increased in the order of $\mathrm{BAG}<\mathrm{BOEG}<\mathrm{BOG}<\mathrm{BSG}$. This indicates that the order of the thermodynamically favorable conditions for a higher conversion of $\mathrm{Fe}_{2} \mathrm{O}_{3}$ is the syngas of $\mathrm{BSG}$ followed by $\mathrm{BOG}, \mathrm{BOEG}$, and BAG. This can be explained by the fact that the reduction capability of $\mathrm{H}_{2}$ is superior to $\mathrm{CO}$ in terms of thermodynamics; thus, the biomass syngas that contains a higher $\mathrm{H}_{2}$ content has a lower thermodynamic reduction temperature for iron oxide.

To determine whether hematite can be reduced to metallic iron under these four kinds of biomass syngas, the reaction process of $\mathrm{Fe}_{2} \mathrm{O}_{3}$ with the four biomass syngas under excess gas supply should be revealed. Figure 2 presents the equilibrium compositions of $0.01 \mathrm{~mol} \mathrm{Fe}_{2} \mathrm{O}_{3}$ with $1.00 \mathrm{~mol}$ biomass syngas at 273-1 $673 \mathrm{~K}$. It can be seen that $\mathrm{Fe}_{2} \mathrm{O}_{3}$ was completely converted to Fe in all four biomass syngas, 

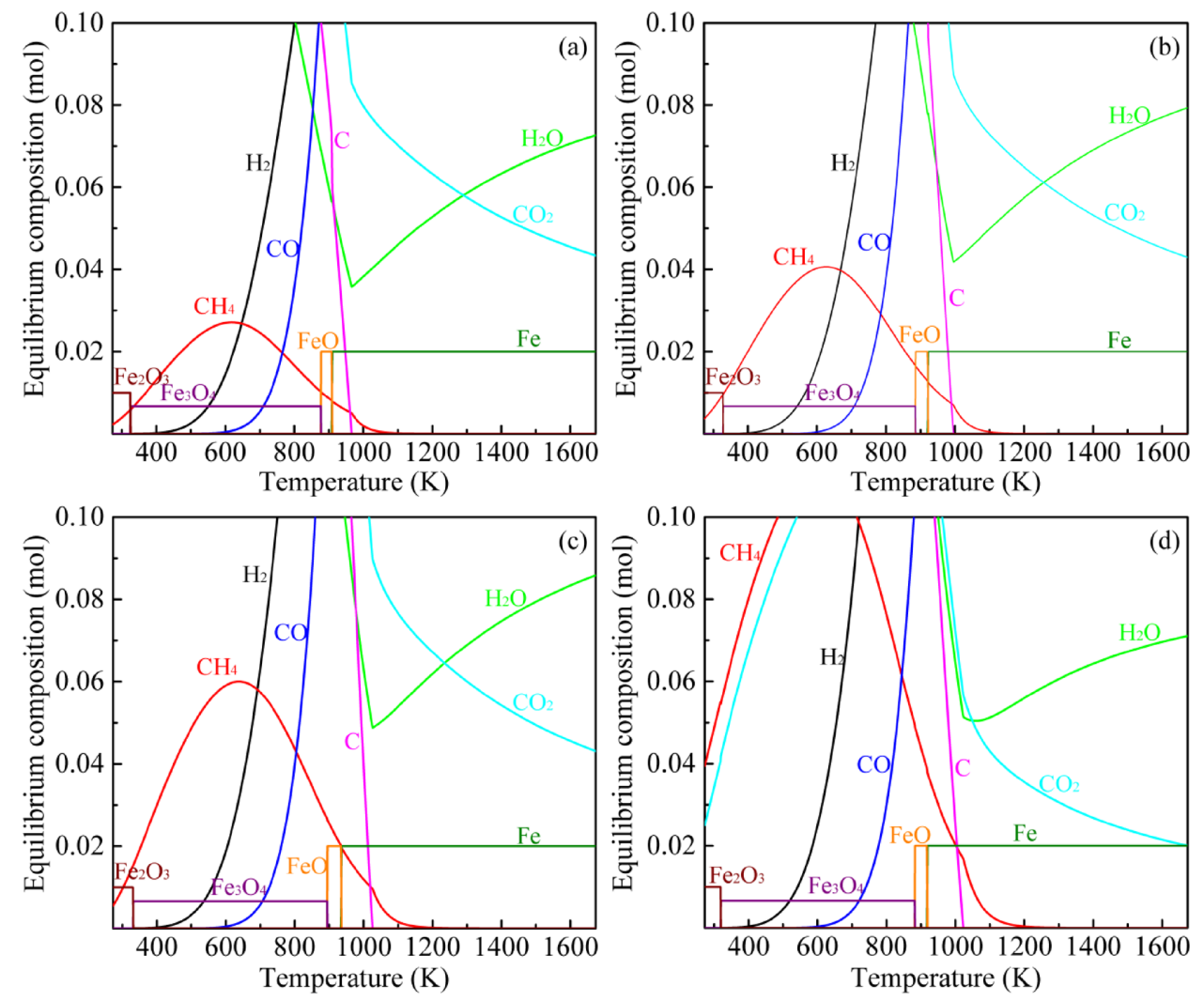

Fig. 2. Equilibrium compositions of 0.01 mole $\mathrm{Fe}_{2} \mathrm{O}_{3}$ with 1.0 mole different biomass syngas: (a) BAG, (b) BOEG, (c) BOG, and (d) BSG. (Online version in color.)

which represents the theoretical maximum conversion possible under the given conditions. This means that hematite can be fully reduced by biomass syngas at high temperatures by controlling the reductive gas content. These results show that it is thermodynamically feasible to use biomass syngas as a reductant in flash ironmaking technology.

\section{Mathematical Model}

\subsection{Model Description}

Because this study focuses on stable trends, a steady-state model was built to simulate the flash reduction process. Influenced by the reactor, ${ }^{26}$ ) the volume fraction of hematite ore particles in the reactor was less than $10^{-6}$ in this study, and interactions between particles in the reactor were neglected due to the low volume fraction of particles. Thus, a 3D steady-state CFD model based on the Euler-Lagrange approach was solved to simulate the hematite flash reduction process in a drop tube reactor. Gases in the reactor, including $\mathrm{CO}, \mathrm{H}_{2}, \mathrm{CH}_{4}, \mathrm{CO}_{2}, \mathrm{H}_{2} \mathrm{O}$ and $\mathrm{N}_{2}$, were modeled as the continuous phase using the incompressible ideal gas law. Hematite particles were assumed to be spherical and were treated with the discrete phase model. Treating the heat and mass losses of particle phase as the terms in the governing equations was used to model the interactions between the particle and gas phases. The turbulence in the gas phase was realized by the realizable $k-\varepsilon$ model, and a stochastic tracking model was applied to analyze the effect of turbulence on particles. The mixing and transport of gas species during the reduction process were realized by applying the species transport model. The homogeneous reaction rates were obtained by the Finite-Rate/Eddy-Dissipation model, which computed both the Arrhenius rate and the eddy dissipation rate and used the minimum of the two. The discrete ordinates radiation model was used to calculate radiative heat transfer. The governing equations for the gas and particle phases are given in Table $\mathbf{3}$.

Once entering a reactor, hematite particles were drastically heated and reduced by the reductive gas. Although the reduction of hematite proceeded via a stepwise pathway $\left(\mathrm{Fe}_{2} \mathrm{O}_{3} \rightarrow \mathrm{Fe}_{3} \mathrm{O}_{4} \rightarrow \mathrm{FeO} \rightarrow \mathrm{Fe}\right)$, the overall reduction process $\mathrm{Fe}_{2} \mathrm{O}_{3} \rightarrow \mathrm{Fe}$ (Eqs. (R12) and (R13)) was adopted in this study since it was difficult to obtain the intrinsic kinetics of each step within a few seconds through the experiment. Thus, most studies on iron ore flash reduction have only reported the reduction kinetics of the overall reduction process instead of the kinetics of each step of the reduction process. ${ }^{18-23)}$ Based on the literature search, Fan et al. ${ }^{26)}$ established a CFD model of hematite flash reduction in a drop tube reactor to modify the reduction kinetics expression, which is more accurate than the experimental expression. The reduction kinetics rate of hematite reported by Fan et $a .^{26)}$ were applied in this model, as listed in Table 4. In terms of the results of thermodynamics analysis in Section 2 , the reversible reactions of WGSR and MSRR were considered in this model. The forward and backward rates of these reversible reactions are related by the equilibrium constant $K$. The WGSR can be catalyzed by both iron and iron oxides. ${ }^{27)}$ However, the particle volume fraction in the reactor was on the order of $10^{-6}$, and therefore the catalysis of iron and iron oxides can be negligible. Considering the non-catalytic condition and the short gas residence time, the reaction rate of the WGSR reported by Bustamante et $a .^{27,28)}$ were applied in this model. However, few stud- 
Table 3. The governing equations for gas and particle phases.

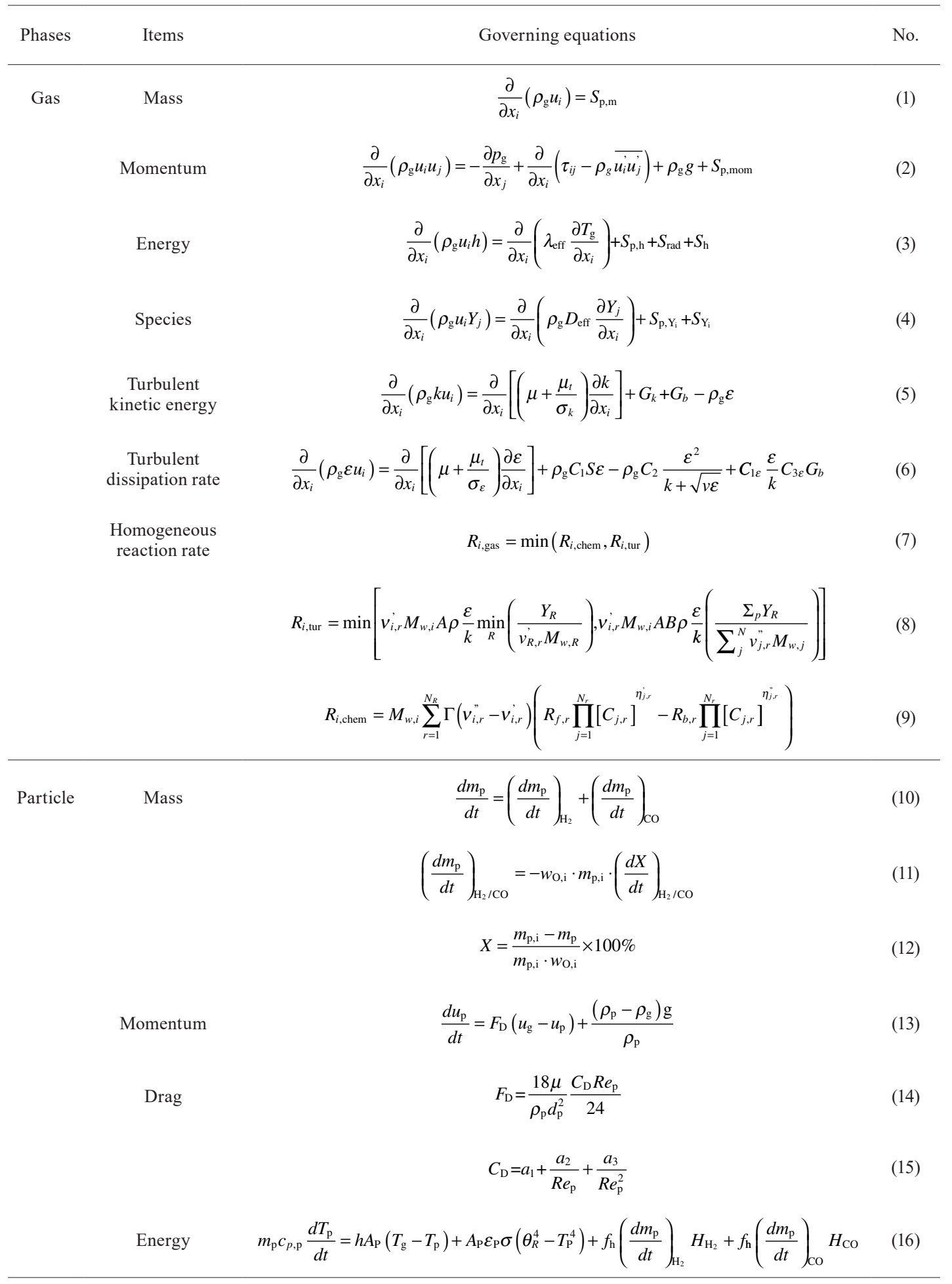

ies on the MSRR rate under similar conditions have been reported. To investigate the effect of the MSRR rate on the flash reduction, different reaction rates were employed and compared.

$$
\begin{aligned}
& \mathrm{Fe}_{2} \mathrm{O}_{3}+3 \mathrm{H}_{2} \rightarrow 2 \mathrm{Fe}+3 \mathrm{H}_{2} \mathrm{O} \\
& \mathrm{Fe}_{2} \mathrm{O}_{3}+3 \mathrm{CO} \rightarrow 2 \mathrm{Fe}+3 \mathrm{CO}_{2}
\end{aligned}
$$

\subsection{Computation Scheme}

In this study, ANSYS Fluent 17.0 software was used to realize the above model. The reaction rates were considered with the help of user-defined function (UDF). Using the SIMPLE method of coupling velocity and pressure, the velocity correction was realized to satisfy continuity. Iterative calculations were performed alternately between continuous and discrete phases until the convergence criteria were met.

\subsection{Computation Domain}

The drop tube reactor in this model contained a vertical reaction tube with an inner diameter of $5.6 \mathrm{~cm}$ and a length 
Table 4. Considered chemical reactions and their reaction rates.

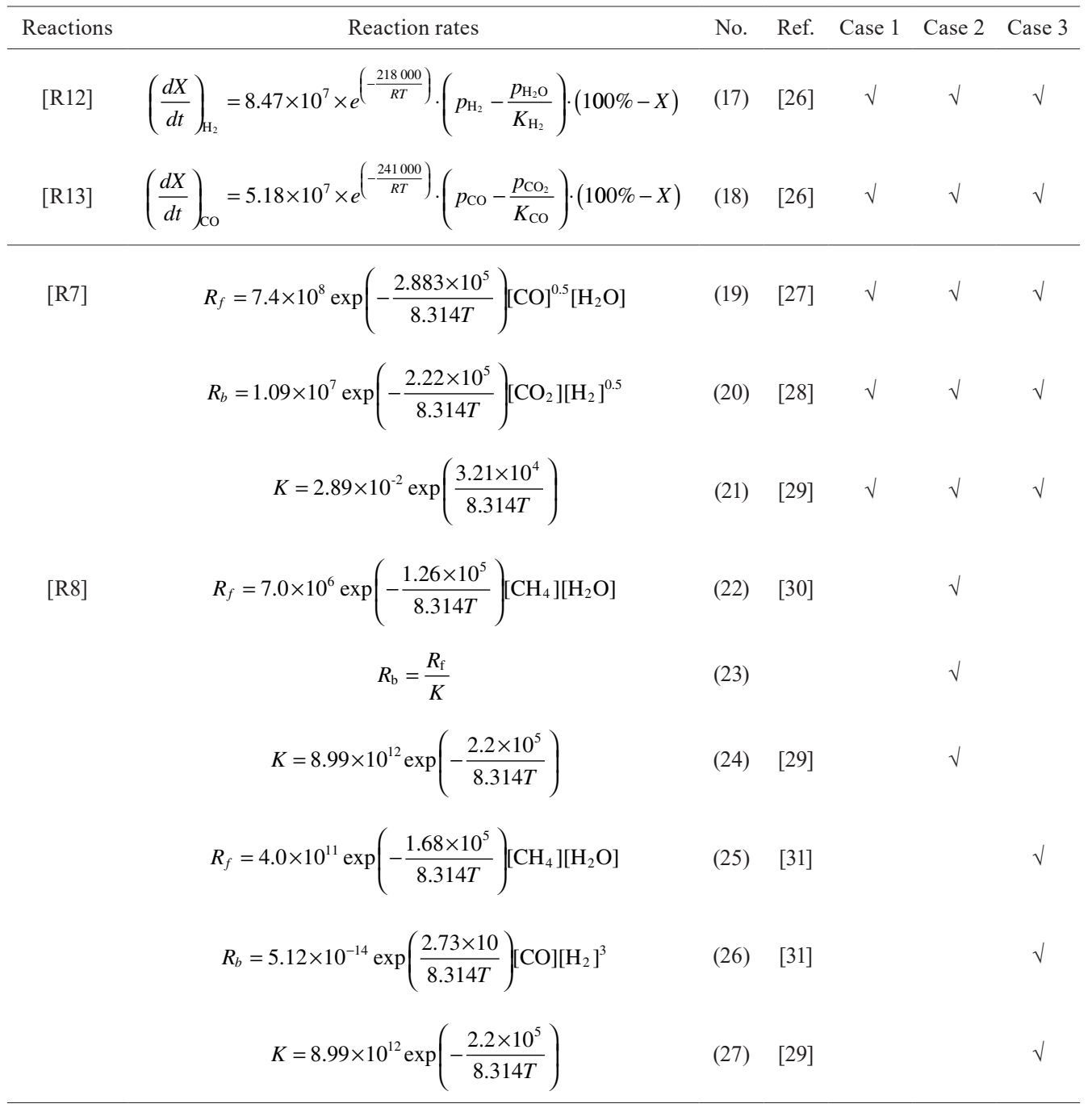

of $195 \mathrm{~cm}$. The length of the isothermal zone was $120 \mathrm{~cm}$. Hematite ore particles carried by the feeder gas entered the reactor from the powder feeding tube at the reactor top, and the gas containing particles flowed downward and exited from the reactor outlet. The structure of the drop tube reactor and associated experimental procedures were described in detail in previous publications. ${ }^{32,33)}$

As shown in Fig. 3, a 3D geometric model of this reactor was built, and the computational domain was extended from 0 to $120 \mathrm{~cm}$ in the axial direction, which represents the isothermal zone of the reaction tube. The reliability of the simulation results was guaranteed by a high-quality grid with 153600 cells, suitable models for physical phenomena, appropriate numerical methods, and good convergence. More detailed boundary conditions of this model were described in our previous study. ${ }^{34)}$

In this study, concentrate particles were assumed to be pure $\mathrm{Fe}_{2} \mathrm{O}_{3}$ with a particle size of $74 \mu \mathrm{m}$. At room temperature, hematite particles were carried by a $0.3 \mathrm{NL} / \mathrm{min}$ feeder gas to enter the reactor from the particle inlet. The roomtemperature biomass syngas flow, composed of $\mathrm{H}_{2}, \mathrm{CH}_{4}$, $\mathrm{CO}, \mathrm{CO}_{2}$, and $\mathrm{N}_{2}$, was introduced into the reactor from the gas inlet. The particle mass rate was fixed as $1 \mathrm{mg} / \mathrm{s}$, and the total gas flow rate including the feeder gas and main gas flow was set at $6.0 \mathrm{NL} / \mathrm{min}$. The operation pressure was

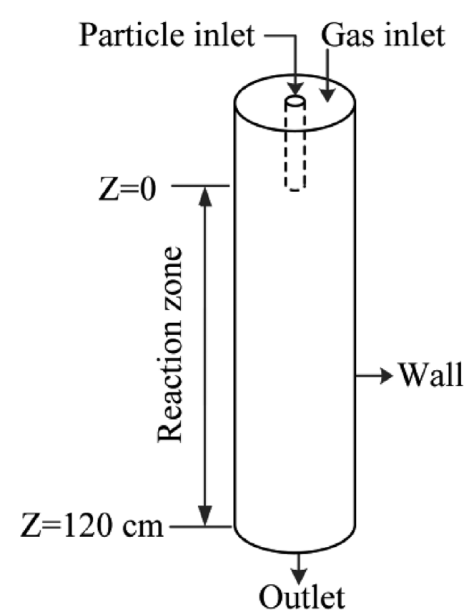

Fig. 3. The schematic diagram of the drop tube furnace.

fixed at $1.0 \mathrm{~atm}$.

\section{Results and Discussion}

\subsection{Model Validation}

The reliability of the model was verified by the hematite ore flash reduction behaviors in $\mathrm{H}_{2}$ and $\mathrm{CO}$ atmosphere. In our previous work, ${ }^{34)}$ to verify the accuracy of the model, 
the predicted reduction degree at the reactor exit was compared with the experimental data reported by Chen et al. ${ }^{32,33)}$ The comparison results are presented in Tables $\mathbf{5}$ and $\mathbf{6}$,

Table 5. Comparison of reduction degree between simulation and experiment in $\mathrm{H}_{2}$ atmosphere.

\begin{tabular}{ccccc}
\hline & & $V_{\mathrm{H}_{2}}$ & \multicolumn{2}{c}{ Reduction degree $(-)$} \\
\cline { 4 - 5 }$T(\mathrm{~K})$ & $P_{\mathrm{H}_{2}}(\mathrm{~atm})$ & $(\mathrm{NL} / \mathrm{min})$ & Experimental $^{32)}$ & Simulated \\
\hline 1473 & 0.2 & 0.9 & 0.54 & 0.56 \\
1473 & 0.2 & 1.5 & 0.37 & 0.39 \\
1473 & 0.2 & 1.9 & 0.33 & 0.31 \\
1523 & 0.2 & 0.9 & 0.75 & 0.76 \\
1523 & 0.2 & 1.5 & 0.57 & 0.57 \\
1523 & 0.2 & 1.9 & 0.43 & 0.47 \\
1623 & 0.1 & 0.4 & 0.89 & 0.89 \\
1623 & 0.1 & 0.7 & 0.67 & 0.7 \\
1623 & 0.1 & 0.9 & 0.61 & 0.6 \\
\hline
\end{tabular}

Table 6. Comparison of reduction degree between simulation and experiment in $\mathrm{CO}$ atmosphere.

\begin{tabular}{|c|c|c|c|c|}
\hline \multirow{2}{*}{$T(\mathrm{~K})$} & \multirow{2}{*}{$P_{\mathrm{CO}}(\mathrm{atm})$} & \multirow{2}{*}{$\begin{array}{c}V_{\mathrm{CO}} \\
(\mathrm{NL} / \mathrm{min})\end{array}$} & \multicolumn{2}{|c|}{ Reduction degree (-) } \\
\hline & & & Experimental $^{33)}$ & Simulated \\
\hline 1473 & 0.6 & 1.5 & 0.34 & 0.34 \\
\hline 1473 & 0.6 & 3 & 0.18 & 0.17 \\
\hline 1473 & 0.85 & 2.2 & 0.42 & 0.4 \\
\hline 1573 & 0.45 & 0.7 & 0.73 & 0.76 \\
\hline 1573 & 0.45 & 1.1 & 0.64 & 0.64 \\
\hline 1623 & 0.45 & 0.7 & 0.85 & 0.91 \\
\hline 1623 & 0.45 & 1.1 & 0.8 & 0.82 \\
\hline 1623 & 0.45 & 1.7 & 0.71 & 0.67 \\
\hline
\end{tabular}

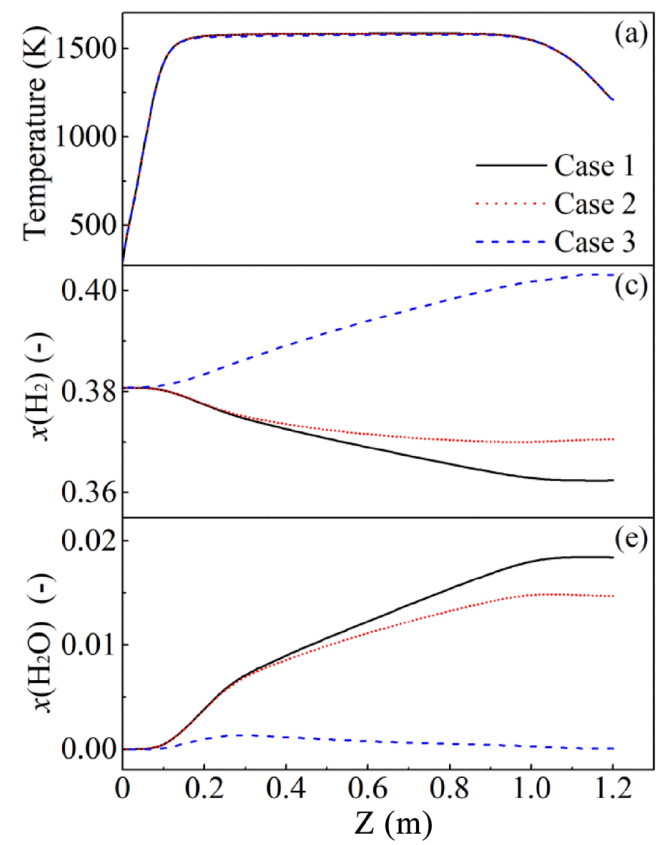

which indicates a good match between the experimental and predicted results. Thus, this CFD model can provide reasonable accuracy for predicting the flash reduction behavior of hematite particles.

\subsection{Effect of Methane Steam Reforming Reaction}

Table 7 presents the predicted particle residence time and reduction degree at the reactor exit under the biomass syngas of BAG, BOEG, BOG, and BSG at $1573 \mathrm{~K}$. In order to investigate the effect of MSRR on the flash reduction process, the results were obtained for the different cases in Table 4. Case 1 ignored the MSRR, while cases 2 and 3 considered different MSRR rates. From Table 7, cases 2 and 3 predicted a higher reduction degree than case 1 using all biomass syngas, which indicates that the MSRR increased the reduction degree. The difference between the results of cases 2 and 3 indicates that the reduction process is slightly sensitive to the MSRR rate.

The reduction degree of hematite was related to the temperature and composition of the gas. In order to explain the positive effect of MSRR on the hematite reduction behavior, Fig. 4 presents the gas temperature and composition in the reactor center-line predicted by different cases at $1573 \mathrm{~K}$ using BOG syngas. Figure 4(a) shows the gas temperature curves calculated by the models in case 1 , case 2 and case

Table 7. Effect of homogeneous reaction rate on the reduction degree of hematite at $1573 \mathrm{~K}$.

\begin{tabular}{ccccc}
\hline \multirow{2}{*}{$\begin{array}{c}\text { Biomass } \\
\text { syngas }\end{array}$} & $\begin{array}{c}\text { Residence } \\
\text { time (s) }\end{array}$ & \multicolumn{3}{c}{ Reduction degree (\%) } \\
\cline { 3 - 5 } & 1.44 & 70.96 & 71.09 & 73.12 \\
BAG & 1.43 & 80.71 & 80.83 & 82.09 \\
BOEG & 1.41 & 88.67 & 88.85 & 92.18 \\
BOG & 1.39 & 95.87 & 95.90 & 96.33 \\
BSG & & & & Case 2 \\
\hline
\end{tabular}

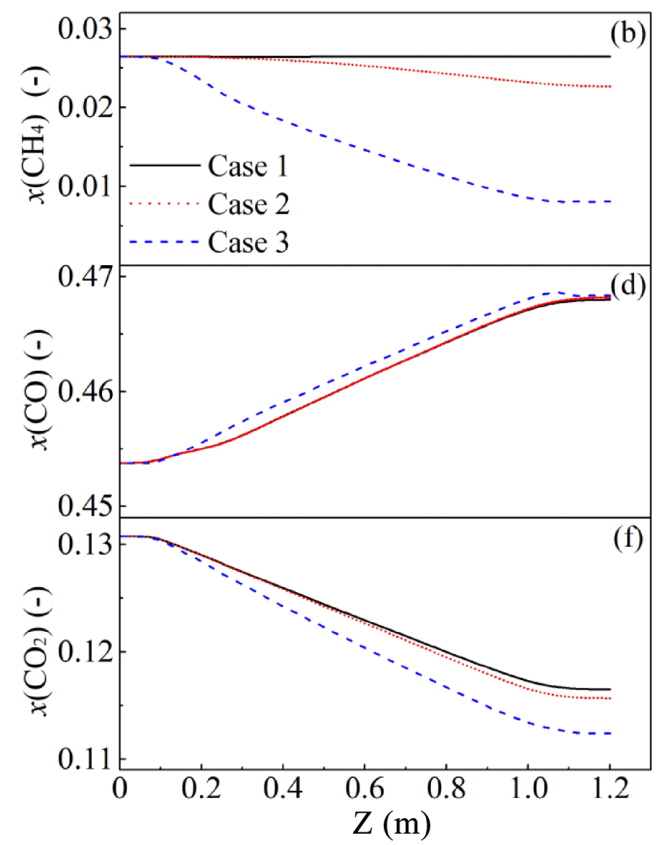

Fig. 4. Profiles of gas temperature and composition along the reactor center-line predicted by different cases at $1573 \mathrm{~K}$ under BOG syngas: (a) gas temperature, (b-f) gas composition. (Online version in color.) 
3. The calculated temperature curves made little difference, which means that the MSRR hardly affected the gas temperature. However, the MSRR promoted the formations of $\mathrm{H}_{2}$ and $\mathrm{CO}$ and inhibited the formation of $\mathrm{H}_{2} \mathrm{O}$ and $\mathrm{CO}_{2}$. Then, the $\mathrm{H}_{2}$ and $\mathrm{CO}$ produced by the MSRR increased the reduction degree of hematite. It can be inferred that the change of reduction degree caused by the MSRR was mainly due to the gas composition change. However, the MSRR had a weak effect on the reduction process as a result of the shorter particle and gas residence time and the slower MSRR rate. Case 3 has a faster forward rate of the MSRR than case 2, so the amount of $\mathrm{H}_{2}$ and $\mathrm{CO}$ converted by $\mathrm{CH}_{4}$ is higher. Thus, the reduction degree predicted by case 3 is higher than case 2, but this difference is minor due to the small amount of $\mathrm{CH}_{4}$ in the syngas. To evaluate the minimum standard for the flash reduction of hematite ore in biomass syngas, the reaction rates of case 2 were used to explore the flash reduction process under different conditions in the following sections.

\subsection{Flash Reduction Behavior}

Figures 5 and $\mathbf{6}$ display the flash reduction behavior inside the reactor at $1573 \mathrm{~K}$ under the BOG syngas, including gas temperature, the mole fraction of main gas species, particle trajectory, and reaction rates in the vertical center plane of the reactor. Due to wall heating, the gas temperature increased rapidly from room temperature to the reduction temperature (Fig. 5(a)). Homogeneous and heterogeneous reactions occurred at certain temperatures, leading to changes in the mole fractions of gas species. From Fig. 6, the forward MSRR $\left(\mathrm{CH}_{4}+\mathrm{H}_{2} \mathrm{O} \rightarrow \mathrm{CO}+3 \mathrm{H}_{2}\right)$ (Fig. 6(a)) and backward WGSR $\left(\mathrm{H}_{2}+\mathrm{CO}_{2} \rightarrow \mathrm{CO}+\mathrm{H}_{2} \mathrm{O}\right)$ (Fig. 6(d)) occurred in the reactor, while the backward MSRR $\left(\mathrm{CO}+3 \mathrm{H}_{2} \rightarrow \mathrm{CH}_{4}+\mathrm{H}_{2} \mathrm{O}\right)$ (Fig. 6(b)) and forward WGSR $\left(\mathrm{CO}+\mathrm{H}_{2} \mathrm{O} \rightarrow \mathrm{H}_{2}+\mathrm{CO}_{2}\right)$ (Fig. 6(c)) did not occur. The forward MSRR (Fig. 6(a)) converts $\mathrm{CH}_{4}$ and $\mathrm{H}_{2} \mathrm{O}$ into $\mathrm{H}_{2}$ and $\mathrm{CO}$, but only a small amount of $\mathrm{CH}_{4}$ was converted in the flash reduction process (Fig. 5(b)) because of the slow rate of the forward MSRR, which had little effect on

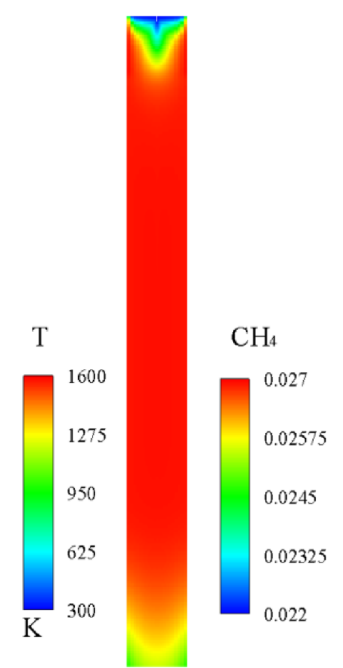

(a)

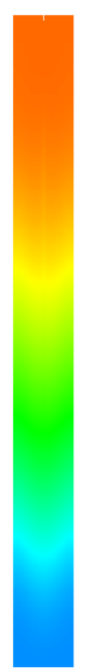

(b)

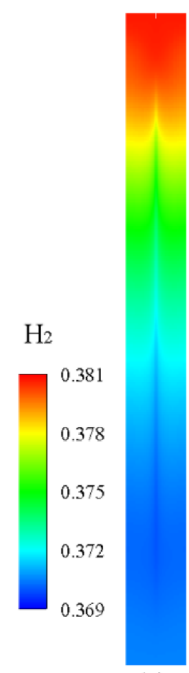

(c)

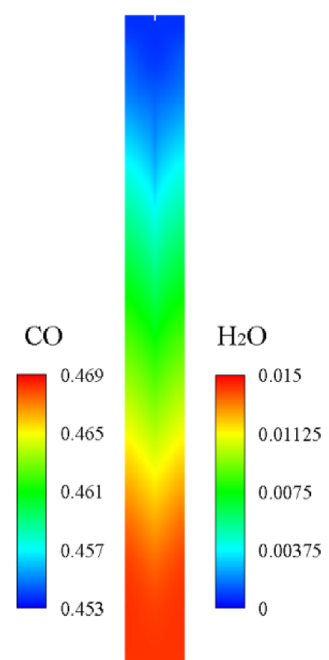

(d)

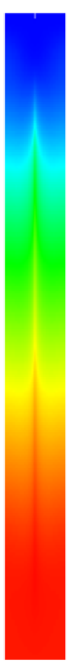

(e)

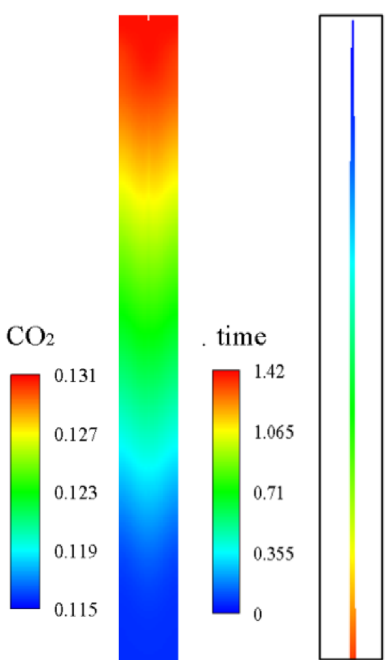

(f) (g)

Fig. 5. Flash reduction behavior in the vertical center plane of the reactor at $1573 \mathrm{~K}$ under syngas of BOG: (a) temperature distribution, $(\mathrm{b}-\mathrm{f})$ gas species mole fraction distribution, and $(\mathrm{g})$ particle trajectory colored with the residence time. (Online version in color.)

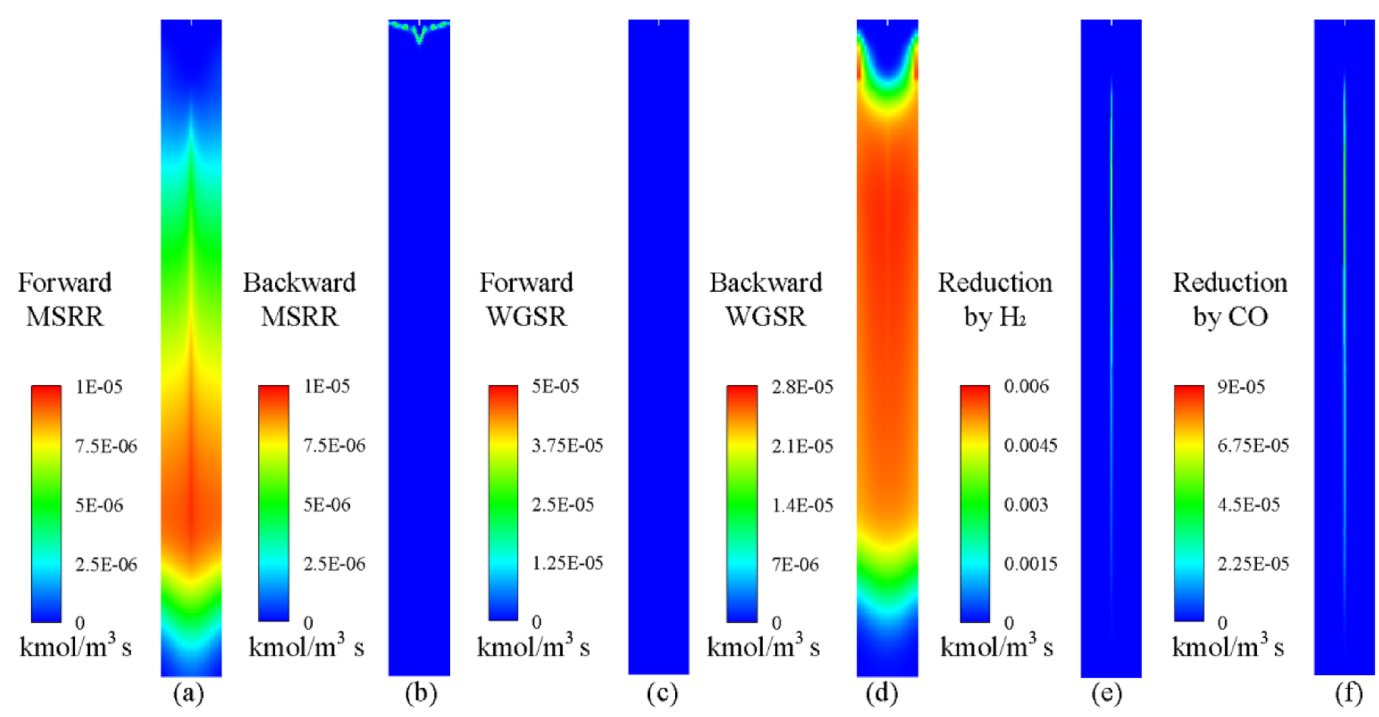

Fig. 6. Contours of reaction rates predicted by case 2 at $1573 \mathrm{~K}$ under BOG syngas: (a-b) forward and backward MSRR, (c-d) forward and backward WGSR, and (e-f) reduction by $\mathrm{H}_{2}$ and $\mathrm{CO}$. (Online version in color.) 
changes in syngas composition. The mole fraction of $\mathrm{H}_{2}$ constantly decreased (Fig. 5(c)) and the mole fraction of $\mathrm{H}_{2} \mathrm{O}$ constantly increased (Fig. 5(e)) due to the backward WGSR (Fig. 6(d)) and the reduction reaction of hematite by $\mathrm{H}_{2}$ (Fig. 6(e)). The $\mathrm{CO}$ content gradually increased (Fig. $5(\mathrm{~d})$ ) and the $\mathrm{CO}_{2}$ content gradually decreased from the reactor inlet to the reactor outlet (Fig. 5(f)). This is because $\mathrm{CO}$ was not only consumed by the reduction of hematite by CO (Fig. 6(f)) but also produced by the backward WGSR (Fig. 6(d)). Moreover, the mole fractions of gas species in the reactor center are more sensitive than in other areas, as shown in Fig. 5. This is reasonable since, in addition to the homogeneous reaction, the syngas in the reactor center also participated in the reduction of hematite ore, which accelerated changes in gas concentration in the reactor center. However, the mole fraction of gas species changed only slightly at $\mathrm{Z}>1.0 \mathrm{~m}$ because the gas temperature was not high enough for the reactions, as shown in Fig. 4.

To further describe the reduction state of hematite particles in the flash reduction process, Fig. 7 illustrates the evolution of the average particle temperature, reduction rate, and reduction degree as a function of the particle resi-

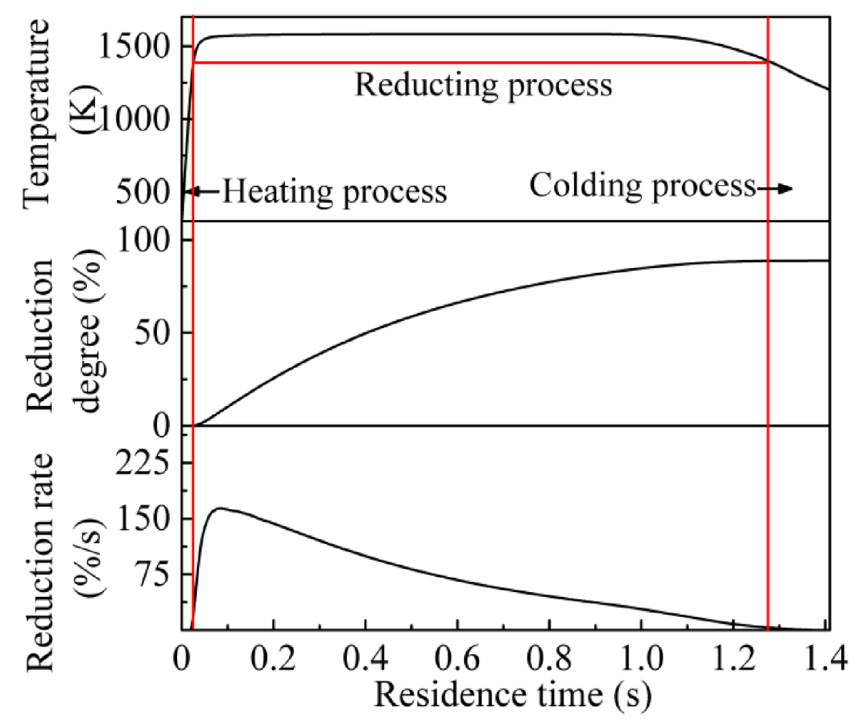

Fig. 7. The time evolution of average particle temperature, reduction rate, and reduction degree at $1573 \mathrm{~K}$ under BOG syngas. (Online version in color.) dence time. The particle temperature and reduction degree were obtained by averaging all particle streams. The reduction rate was determined by calculating the instantaneous slope of the reduction degree curve. From Fig. 7, hematite particles in the reactor undergo three processes, namely, the heating process, the reduction process, and the cooling process. The particle temperature rapidly increased after entering the reactor. When the particle temperature reached $1400 \mathrm{~K}$ in $0.02 \mathrm{~s}$, the reduction process begins. The reduction rate increased gradually until the particle temperature reached its maximum, then it decreased upon increasing the reduction degree, resulting in the reduction degree curve first increasing rapidly and then gradually flattening. When the particle temperature was below $1400 \mathrm{~K}$, the reduction rate tended to 0 , and the reduction rate was so low that the reduction reaction no longer occurred.

\subsection{Sensitivity Analysis}

The operating conditions, such as reduction temperature, gas composition, and pressure, were the main factors affecting the reduction process inside a reactor. Hence, a sensitivity analysis was conducted to investigate the effects of these operating parameters on the flash reduction behavior, including the reduction degree and particle residence time.

\subsubsection{Effect of Gas Composition}

Figure 8 describes the effect of biomass syngas composition on the flash reduction behavior of hematite. The residence time of particles was obtained by the reactor length and particle velocity. The particle velocity is related to the gas velocity and particle density. At a certain gas flow rate, the gas velocity is affected by the temperature, so the particle velocity is also affected by temperature. It leads to the different residence times of particles at different temperatures, as shown in Fig. 8(a). Moreover, the reduction degree of hematite particles at different temperatures and atmospheres was different, that is, the density of reduced hematite particles was different under different reduction conditions, which will also affect the residence time of hematite particles in the reactor.

In Fig. 8(a), the reduction degree under BSG syngas with the highest $\mathrm{H}_{2}$ content among all gas compositions was the highest at all temperatures, reaching $95.9 \%$ at $1573 \mathrm{~K}$ with a particle residence time of $1.39 \mathrm{~s}$. In contrast, BAG syn-
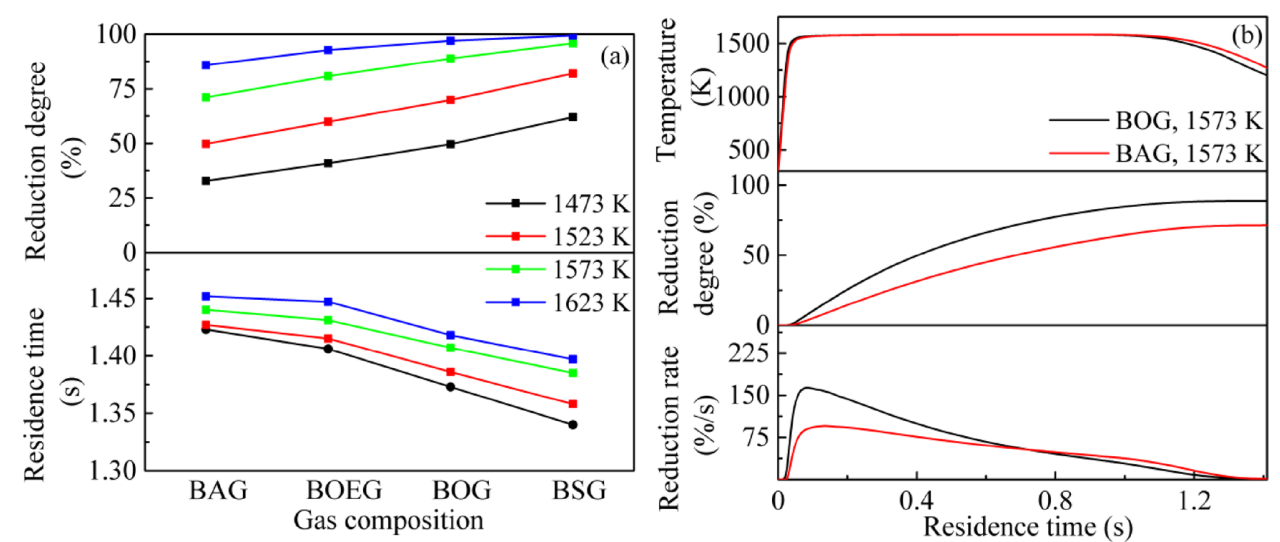

Fig. 8. Effect of gas composition on (a) reduction degree and particle residence time at the reactor exit, (b) time evolution of average particle temperature, reduction rate and reduction degree. (Online version in color.) 
gas, which had the lowest $\mathrm{H}_{2}$ content, displayed the lowest reduction degree at all temperatures, reaching $71.08 \%$ at $1573 \mathrm{~K}$ with a particle residence time of $1.44 \mathrm{~s}$. From Fig. $8(\mathrm{~b})$, the temperature variation of hematite particles under different atmospheres was very similar, but the reduction rate in BOG was higher than BAG. This is because the reduction rate of $\mathrm{H}_{2}$ is higher than that of $\mathrm{CO}$, and increasing the $\mathrm{H}_{2}$ content in biomass syngas increased the reduction rate of hematite more easily compared with $\mathrm{CO}$. The reduction degree trended from lowest to highest as follows: $\mathrm{BAG}<\mathrm{BOEG}<\mathrm{BOG}<\mathrm{BSG}$, which is in agreement with the thermodynamic analysis. Thus, syngas from biomass steam gasification is more suitable for the flash ironmaking technology compared with biomass air or oxygen gasification.

To reveal the homogeneous reactions occurring in the reactor, Fig. 9 shows the WGSR and MSRR rate profiles along the reactor center-line at $1573 \mathrm{~K}$. It can be observed that the WGSR proceeds in the reverse direction, and the MSRR almost moves in the positive direction in the reactor under these four biomass syngas. The reduction using BOG syngas has the fastest rate of the forward MSRR, followed by the reduction process in syngas of BOEG, BAG, and BSG. This can be explained by the fact that BOG syngas

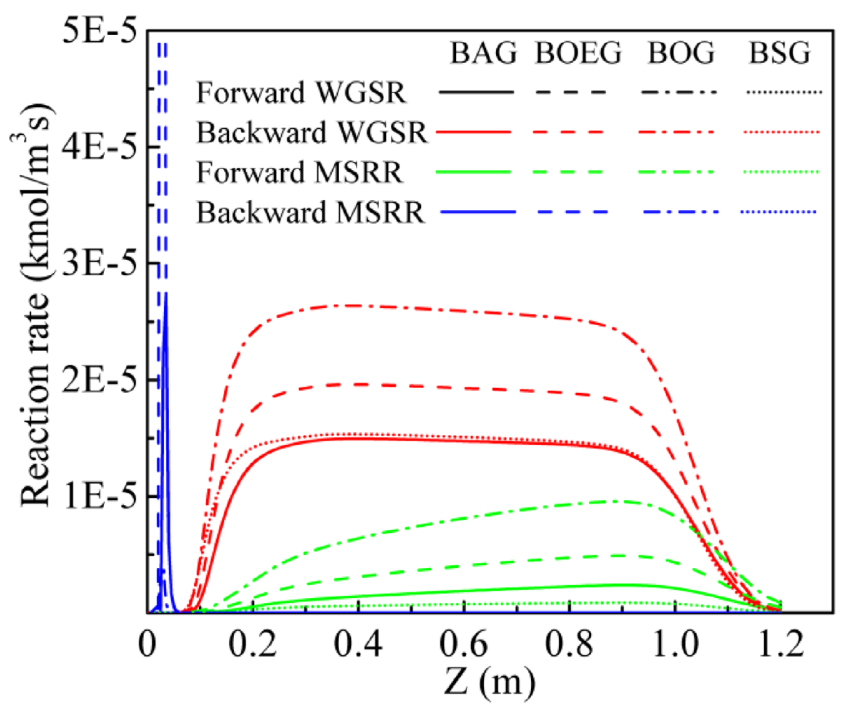

Fig. 9. Reaction rates along the reactor center-line at $1573 \mathrm{~K}$ under different atmosphere. (Online version in color.)

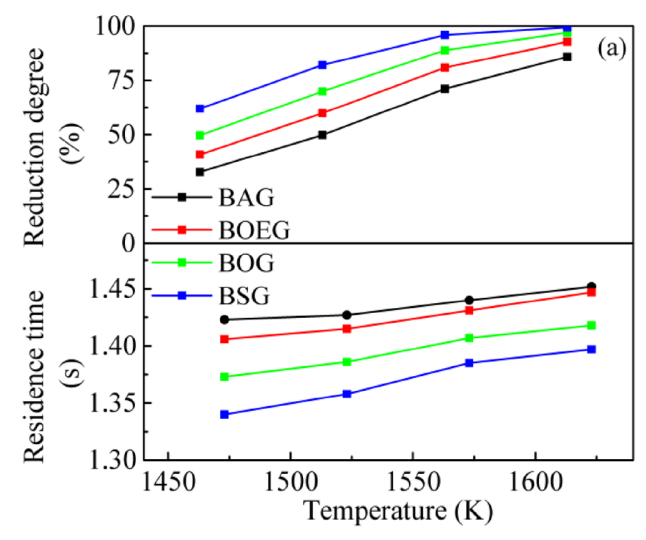

has the highest $\mathrm{CH}_{4}$ content.

\subsubsection{Effect of Reduction Temperature}

The thermodynamic analysis in Section 2 indicated that hematite could be completely converted to iron by all four biomass syngas at $1273-1673 \mathrm{~K}$. However, due to the extremely short particle residence time and the limitations of reduction reaction kinetics, hematite may only be partly converted to iron in the flash reduction process. Thus, it is necessary to further investigate the flash reduction behavior of hematite at different temperatures. Figure $\mathbf{1 0}$ shows the effect of reduction temperature on the flash reduction behavior of hematite under four biomass syngas. The residence time of particles is related to the particle velocity. Increasing the temperature causes an increase in gas velocity, which leads to an increase in particle velocity and a decrease in particle residence time. However, increasing the temperature also accelerates the particle mass loss rate caused by reduction reactions, leading to a decline in the particle velocity and an increase in the particle residence time. After taking into account both factors, the particle residence time increased slightly as the temperature increased, as shown in Figs. 8(a) and 10(a). Moreover, the temperature had a

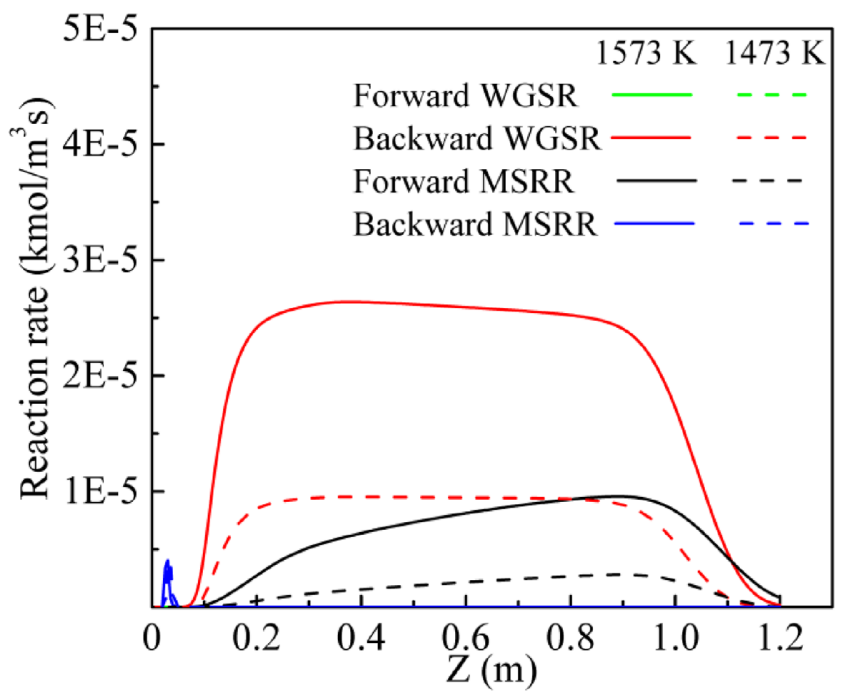

Fig. 11. Reaction rates along the reactor center-line at different temperatures under BOG syngas. (Online version in color.)

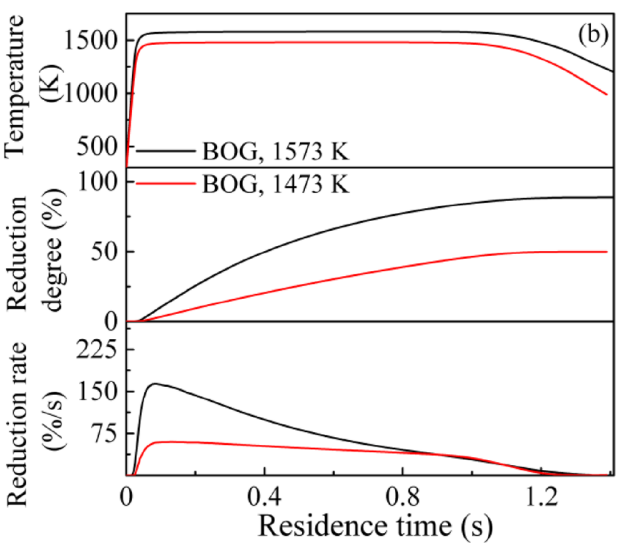

Fig. 10. Effect of temperature on (a) reduction degree and particle residence time at the reactor exit, (b) time evolution of average particle temperature, reduction rate, and reduction degree. (Online version in color.) 

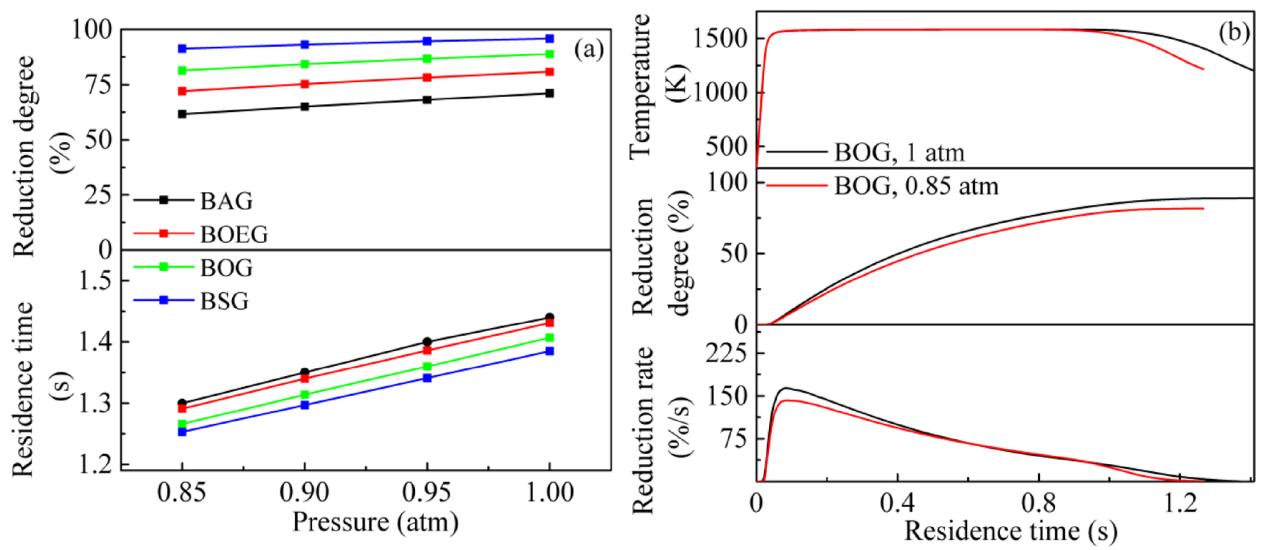

Fig. 12. Effects of operating pressure on (a) reduction degree and particle residence time at the reactor exit, (b) time evolutions of average particle temperature, reduction rate, and reduction degree. (Online version in color.)

strong positive effect on the reduction degree. In all syngas, the reduction degree was very low $(29.27 \%$ to $58.68 \%)$ at $1473 \mathrm{~K}$, while it reached the maximum $(84.41 \%$ to $99.16 \%)$ at $1623 \mathrm{~K}$. It can be seen that increasing the reduction temperature is an effective way to enhance the reduction degree of hematite, which is in agreement with the study of Qu et al. ${ }^{35)}$ From Fig. 10(b), this is reasonable because that increasing the temperature enhanced the particle temperature, which increased the reduction rate.

Figure 11 describes the effect of temperature on the profiles of WGSR and MSRR rates along the reactor centerline. It can be found that WGSR proceeded in the backward direction, while MSRR proceeded in the forward direction. Raising the temperature does not change the reaction direction. This is because the backward WGSR and forward MSRR are thermodynamically favored at high temperatures. In addition, a high temperature increased the reaction rates of the backward WGSR and forward MSRR.

\subsubsection{Effect of Pressure}

The reduction behavior of hematite under the four biomass syngas at different pressures was studied at $1573 \mathrm{~K}$, and the results are presented in Fig. 12. From Fig. 12(a), it can be observed that increasing the pressure increased the reduction degree and slightly extended the particle residence time. Because a slight increase in the particle residence time did not obviously increased the reduction degree, the particle characteristics in the flash reduction process were described to explain this. In Fig. 12(b), the particle temperature only weakly changed upon increasing the pressure, but the reduction rate increased because increasing the operating pressure increased the partial pressure of the reducing gas. Hence, the increase in the reaction degree upon increasing the operating pressure was attributed to a change in the reduction rate.

\section{Conclusions}

Biomass syngas mainly composed of $\mathrm{H}_{2}, \mathrm{CO}, \mathrm{CH}_{4}$, $\mathrm{CO}_{2}$ and $\mathrm{N}_{2}$ was used as the reducing agent for the flash reduction process of hematite ore. A 3D steady-state CFD model based on the Euler-Lagrange approach was solved to simulate the flash reduction behaviors of hematite with four different biomass syngas in a drop tube reactor. The conclu- sions are summarized as follows:

(1) The thermodynamic analysis indicated that several reactions occur in the reaction system of $\mathrm{Fe}_{2} \mathrm{O}_{3}$ with these four gas mixtures (i.e. biomass air gasification (BAG), biomass $\mathrm{O}_{2}$-enriched air gasification (BOEG), biomass $\mathrm{O}_{2}$ gasification (BOG) and biomass steam gasification (BSG)) at $1273-1673 \mathrm{~K}$, namely, the reduction of hematite by $\mathrm{CO}$ and $\mathrm{H} 2$, the methane steam reforming reaction (MSRR), and the water gas shift reaction (WGSR).

(2) In these four biomass syngas, the volume fraction of $\mathrm{CH}_{4}$ was so low that the MSRR hardly affected the gas temperature, but it promoted the formation of $\mathrm{H}_{2}$ and $\mathrm{CO}$ and inhibited the formation of $\mathrm{H}_{2} \mathrm{O}$ and $\mathrm{CO}_{2}$. Then, the produced $\mathrm{H}_{2}$ and $\mathrm{CO}$ increased the reduction degree of hematite, but this effect was weak due to the shorter particle residence time and slower reaction rate.

(3) Increasing the reduction temperature and pressure are effective ways to enhance the reduction degree of hematite. Moreover, the reduction degree increases with the hydrogen content in the biomass syngas in the following order $\mathrm{BAG}<\mathrm{BOEG}<\mathrm{BOG}<\mathrm{BSG}$. The reduction degree of hematite reached $95.90 \%$ with a particle residence time of $1.39 \mathrm{~s}$ at $1573 \mathrm{~K}$ under the BSG syngas.

(4) The forward MSRR and backward WGSR occurred in the reactor, while the backward MSRR and forward WGSR hardly occurred. Raising the temperature did not change the direction of the reaction. This is because the backward WGSR and forward MSRR are thermodynamically favored at high temperature. In addition, a high temperature increased the reaction rates of the backward WGSR and forward MSRR.

\section{Acknowledgment}

This work is financially supported by National Natural Science Foundation of China (51904066), Liaoning Revitalization Talents Program (XLYC1802032), Fundamental Research Funds for the Central Universities (N182503032), Postdoctoral Foundation of Northeastern University (20190201) and Postdoctoral International Exchange Program (Dispatch Project, 20190075).

\section{Nomenclature}

$A_{\mathrm{p}}$ : Particle surface area $\left(\mathrm{m}^{2}\right)$

$C_{\mathrm{D}}$ : Drag coefficient 
$c_{p}:$ Heat capacity $\left(\mathrm{J} \cdot \mathrm{kg}^{-1} \cdot \mathrm{K}^{-1}\right)$

$D_{\text {eff: }}$ Effective diffusivity coefficient $\left(\mathrm{m}^{2} \cdot \mathrm{s}^{-1}\right)$

$d_{\mathrm{p}}$ : Particle diameter $(\mathrm{m})$

$F_{\mathrm{D}}$ : Drag force per unit particle mass

$f_{\mathrm{h}}$ : Particle reaction heat absorption ratio

$\mathrm{g}$ : Gravitational acceleration $\left(\mathrm{m} \cdot \mathrm{s}^{-2}\right)$

$h$ : Convective heat transfer coefficient $\left(\mathrm{W} \cdot \mathrm{m}^{-2} \cdot \mathrm{K}^{-1}\right)$

$H$ : Enthalpy of reaction $\left(\mathrm{J} \cdot \mathrm{kg}^{-1}\right)$

$k$ : Turbulence kinetic energy reaction $\left(\mathrm{m}^{2} \cdot \mathrm{s}^{-2}\right)$

$K$ : Equilibrium constant of WGSR

$K_{\mathrm{H}_{2}}, K_{\mathrm{CO}}$ : Reaction equilibrium constant of $\mathrm{FeO}$ reduced by $\mathrm{H}_{2}$ and $\mathrm{CO}$

$m_{\mathrm{p}}$ : Instantaneous particle mass $(\mathrm{kg})$

$m_{\mathrm{p}, \mathrm{i}}:$ Initial particle mass $(\mathrm{kg})$

$p_{\mathrm{g}}$ : Gas pressure $(\mathrm{Pa})$

$R_{\mathrm{f}}, R_{\mathrm{b}}$ : Rates of the forward and backward reaction $\left(\mathrm{kmol} \cdot \mathrm{m}^{-3} \cdot \mathrm{s}^{-1}\right)$

$R e_{\mathrm{p}}$ : Particle Reynolds number

$S_{\mathrm{p}, \mathrm{m}}, S_{\mathrm{p} . \mathrm{mon}}, S_{\mathrm{p}, \mathrm{h}}, S_{\mathrm{pYi}}$ : Interphase exchange terms for mass, momentum, enthalpy and species

$S_{\mathrm{h}}, S_{\mathrm{Yi}}$ : Source terms due to homogeneous reactions

$S_{\text {rad: }}$ Radiation source term

$t$ : Particle residence time (s)

$T$ : Temperature $(\mathrm{K})$

$\theta_{R}$ : Radiation temperature $(\mathrm{K})$

$u$ : Velocity $\left(\mathrm{m} \cdot \mathrm{s}^{-1}\right)$

$w_{\mathrm{o}, \mathrm{i}}$ : Initial oxygen mass fraction in particle $(\%)$

$X$ : Reduction degree (\%)

$Y_{\mathrm{i}}$ : Mass fraction of chemical species $\mathrm{i}$

$\varepsilon$ : Dissipation rate of turbulence kinetic energy $\left(\mathrm{m}^{2} \cdot \mathrm{s}^{-3}\right)$

$\varepsilon_{\mathrm{p}}$ : Particle emissivity

$\lambda$ : Thermal conductivity $\left(\mathrm{W} \cdot \mathrm{m}^{-1} \cdot \mathrm{K}^{-1}\right)$

$\mu$ : Viscosity $\left(\mathrm{kg} \cdot \mathrm{m}^{-1} \cdot \mathrm{s}^{-1}\right)$

$\rho$ : Density $\left(\mathrm{kg} \cdot \mathrm{m}^{-3}\right)$

Subscripts

$\sigma$ : Stefan-Boltzmann constant $\left(\mathrm{W} \cdot \mathrm{m}^{-2} \cdot \mathrm{K}^{-4}\right)$
g: Gas
p: Particle
t: Turbulent

\section{REFERENCES}

1) H. Y. Sohn and Y. Mohassab: J. Sustain. Metall., 2 (2016), 216.

2) H. Wang and H. Y. Sohn: Metall. Mater. Trans. B, 44 (2013), 133.

3) S. K. Sansaniwal, K. Pal, M. A. Rosen and S. K. Tyagi: Renew.
Sustain. Energy Rev., 72 (2017), 363.

4) S. Wang, K. Luo, C. Hu, L. Sun and J. Fan: Powder Technol., 333 (2018), 304.

5) S. Kraft, M. Kuba and H. Hofbauer: Powder Technol., 338 (2018), 887.

6) Z. Yao, S. You, T. Ge and C. Wang: Appl. Energy, 209 (2018), 43.

7) Z. Wang, T. He, J. Qin, J. Wu, J. Li, Z. Zi, G. Liu, J. Wu and L. Sun: Fuel, 150 (2015), 386.

8) Y. Cheng, Z. Thow and C. H. Wang: Powder Technol., 296 (2016), 87.

9) H. Suopajärvi, E. Pongrácz and T. Fabritius: Renew. Sustain. Energy Rev., 25 (2013), 511.

10) E. Mousa, C. Wang, J. Riesbeck and M. Larsson: Renew. Sustain. Energy Rev., 65 (2016), 1247.

11) H. Suopajärvi, A. Kemppainen, J. Haapakangas and T. Fabritius: $J$. Clean. Prod., 148 (2017), 709.

12) D. Guo, L. Zhu, S. Guo, B. Cui, S. Luo, M. Laghari, Z. Chen, C. Ma, Y. Zhou, J. Chen, B. Xiao, M. Hu and S. Luo: Fuel Process. Technol., 148 (2016), 276.

13) D. Guo, Y. Li, B. Cui, Z. Chen, S. Luo, B. Xiao, H. Zhu and M. Hu: Chem. Eng. J., 327 (2017), 822.

14) S. Luo, C. Yi and Y. Zhou: Renew. Energy, 36 (2011), 3332

15) Q. Liu, W. Zhong, J. Gu and A. Yu: Powder Technol., 373 (2020), 522.

16) J. Xu, N. Wang, Z. Zhou, M. Chen and P. Wang: Powder Technol., $361(2020), 226$

17) I. Adeyemi, I. Janajreh, T. Arink and C. Ghenai: Appl. Energy, 185 (2017), 1007.

18) D. Q. Fan, H. Y. Sohn, Y. Mohassab and M. Elzohiery: Metall. Mater. Trans. B, 47 (2016), 3489.

19) B. Abolpour, M. M. Afsahi, A. Soltani Goharrizi and M. Azizkarimi: Ironmaking Steelmaking, 44 (2017), 750.

20) A. Abdelghany, D. Q. Fan, M. Elzohiery and H. Y. Sohn: Steel Res. Int., 90 (2019), 1970091.

21) A. Abdelghany, D. Q. Fan and H. Y. Sohn: Metall. Mater. Trans. B, $51(2020), 2046$

22) Y. Yang, D. Li, L. Guo, Z. Wang and Z. Guo: Appl. Therm. Eng., 168 (2020), 114899

23) Y. Yang, L. Guo, D. Li and Z. Guo: Appl. Therm. Eng., 171 (2020), 115067.

24) X. Wang, G. Fu, W. Li and M. Zhu: Powder Technol., 366 (2020), 587.

25) E. Shayan, V. Zare and I. Mirzaee: Energy Convers. Manag., 159 (2018), 30.

26) D. Q. Fan, H. Y. Sohn and M. Elzohiery: Metall. Mater. Trans. B, 48 (2017), 2677.

27) F. Bustamante, R. M. Enick, R. P. Killmeyer, B. H. Howard, K. S. Rothenberger, A. V. Cugini, B. D. Morreale and M. V. Ciocco: AIChE J., 51 (2005), 1440.

28) F. Bustamante, R. M. Enick, A. Cugini, R. Killmeyer, B. H. Howard, K. S. Rothenberger, M. V. Ciocco, B. D. Morreale, S. Chattopadhyay and S. Shi: AIChE J., 50 (2004), 1028.

29) A. Roine: HSC Chemistry 6.0, Outokumpu Technology, Helsinki, (2006).

30) X. Ku, J. Wang, H. Jin and J. Lin: Renew. Energy, 139 (2019), 781.

31) H. Watanabe and M. Otaka: Fuel, 85 (2006), 1935.

32) F. Chen, Y. Mohassab, T. Jiang and H. Y. Sohn: Metall. Mater. Trans. B, 46 (2015), 1133.

33) F. Chen, Y. Mohassab, S. Q. Zhang and H. Y. Sohn: Metall. Mater. Trans. B, 46 (2015), 1716.

34) X. Wang, G. Fu, W. Li and M. Zhu: ISIJ Int, 59 (2019), 2193.

35) Y. X. Qu, Y. X. Yang, Z. S. Zou, C. Zeilstra, K. Meijer and R. Boom: ISIJ Int., 55 (2015), 952. 